\title{
FORMAÇÃO DE MUDAS DE EUCALIPTO COM UTILIZAÇÃO DE LIXO ORGÂNICO E NÍVEIS DE IRRIGAÇÃO CALCULADOS POR DOIS MÉTODOS
}

\author{
JOÃO A. GALBIATTI ${ }^{1}$, JANDISLAU J. LUI ${ }^{2}$, DÉBORA Z. SABONARO ${ }^{3}$, \\ LARA F. BUENO ${ }^{3}$, VANESSA L. DA SILVA ${ }^{4}$
}

\begin{abstract}
RESUMO: O estudo das características e das possibilidades de utilização de Resíduo Sólido Urbano (R.S.U.) e mais especificamente de Resíduo Sólido Orgânico Urbano (R.S.O.U.), no Brasil e no Mundo, ainda não produziu informações que possibilitem conhecimentos suficientes para tomadas de decisões que estão sendo exigidas, em razão do crescente volume de resíduos produzidos e os impactos ao meio ambiente. Este trabalho teve o objetivo de estudar o efeito da irrigação associada ao uso de R.S.O.U. para formação de mudas de eucalipto. A pesquisa foi desenvolvida na UNESP, Câmpus de Jaboticabal - SP, sendo adotado como delineamento estatístico o esquema fatorial inteiramente casualizado. Foram utilizados 11 substratos: dois tipos de solos (um Latossolo Vermelho eutrófico e um Latossolo Vermelho distrófico), com e sem adubação química, seis misturas de solo e R.S.O.U., e um utilizando somente R.S.O.U. Sementes de eucalipto var. Citriodora Hooker foram semeadas diretamente em topetes e irrigadas com base em dois métodos de quantificação da água evapotranspirada (tanque Classe A e determinação da massa), em quatro níveis (50; 70; 100 e 130\% da evapotranspiração). Os dados coletados e analisados estatisticamente demonstraram que doses acima de $20 \%$ de R.S.O.U. na mistura, em solos destinados à produção de mudas de eucalipto, causam efeitos negativos na sobrevivência das plantas.
\end{abstract}

PALAVRAS-CHAVE: eucalipto, resíduo orgânico, substrato.

\section{EFFECT OF ORGANIC GARBAGE AND IRRIGATION LEVELS CALCULATED BY TWO METHODS IN THE EUCALIPTUS SEEDLINGS FORMATION}

\begin{abstract}
Studies of the characteristics and possibilities of utilization the of Urban Solid Residue (U.S.R.) and specifically Urban Organic Solid Residue (U.O.S.R.) have not yet produced information in Brazil and in the world that permits sufficient knowledge for taking necessary decisions for immediate solutions that are demanded due to the increasing volume of residue produced. This work has as objective to study the effects of irrigation associated with the use of U.O.S.R. for growing eucalyptus seedlings. This research was developed at the São Paulo State University - UNESP - Jaboticabal, State of São Paulo, Brazil. The statistical design was a randomized in a factorial array. Eleven substrata were formulated using two types of soil, a EUTRUSTOX and a HAPLUSTOX, with and without chemical fertilization, six mixtures among soils and Urban Organic Solid Residue (U.O.S.R.), and pure U.O.S.R. Citriodora Hooker eucalyptus seeds were used in direct seeding in blocks of soil using two kinds of calculation of water quantity to be applied in the irrigation, through class A tank methods and weighing the substrata, in four levels $(50 \% ; 70 \% ; 100 \%$ and $130 \%$ of evapotranspiration). The collected and statistically analyzed data showed that mixtures of $20 \%$ or more of U.O.S.R presented a harmful effect on plant development in soils for the production of eucalyptus seedlings by direct seeding.
\end{abstract}

KEYWORDS: organic residue, substrate, eucalyptus.

\footnotetext{
${ }^{1}$ Engo Agrônomo, Prof. Titular, Departamento de Engenharia Rural, UNESP, Jaboticabal - SP, Fone: (0XX16) 3209.2637, galbi@fcav.unesp.br

${ }^{2}$ Doutorando em Produção Vegetal, Departamento de Engenharia Rural, UNESP, Jaboticabal - SP.

${ }^{3}$ Mestre em Agronomia, Departamento de Engenharia Rural, UNESP, Jaboticabal - SP.

${ }^{4}$ Mestranda em Ciência do Solo, Departamento de Engenharia Rural, UNESP, Jaboticabal - SP.

Recebido pelo Conselho Editorial em: 6-10-2004
}

Aprovado pelo Conselho Editorial em: 22-6-2007 


\section{INTRODUÇÃO}

No Brasil, de 1970 a 1990, 16 milhões de brasileiros deixaram as áreas rurais rumo aos centros urbanos; atualmente, aproximadamente $77 \%$ dos brasileiros vivem nas cidades. Na cidade do Rio de Janeiro, de cada três moradores, um vive em favela com precário sistema de saneamento e com deposição de lixo a céu aberto (IBGE, 2000).

Não é mais possível viver sem planejar os destinos dos resíduos urbanos. É preciso refletir sobre o que Lavoisier postulou: "na natureza nada se perde, nada se cria, tudo se transforma". Considerando o tão difundido adágio do desenvolvimento sustentável, existe carência de entendimento mais amplo do ciclo de vida dos produtos utilizados pelo homem, cuja extremidade final é a sua incorporação ao ciclo de vida no planeta.

Problemas ambientais seriam reduzidos caso fosse possível utilizar o Resíduo Sólido Orgânico Urbano (R.S.O.U.) na agricultura, ocorrendo economia e melhoria da qualidade de vida. As propriedades físicas e químicas do solo, como a agregação das partículas, a porosidade, a retenção de água, a condutividade hidráulica, a capacidade de campo e a fertilidade são favorecidas pelo uso de matéria orgânica. Esses fatores importantes para a melhoria das condições dos solos agricultáveis podem ainda tornar os solos pobres de baixa sustentabilidade produtiva, economicamente viáveis (KIEHL, 1985; FERNANDEZ et al., 1987; ANDRIOLI et al., 1991 e RUIZ \& TEIXEIRA, 1991).

Com o advento da irrigação, tornou-se possível a produção agrícola em locais antes impossíveis pela falta de chuvas; entretanto, quando feita sem critério, causa o desperdício de grande quantidade de água. Métodos e sistemas modernos de irrigação estão diminuindo a quantidade de água aplicada, colocando o total necessário no local certo, por exemplo, a microaspersão e gotejadores.

Para a produção de mudas, há necessidade de tomarem-se alguns cuidados especiais, entre os quais se destacam a quantidade de água fornecida durante o processo de produção, pois, segundo MAROUELLI \& SILVA (1993), a disponibilidade de água para a planta, na quantidade correta e no momento oportuno, é decisiva para o sucesso da cultura. Para isso, é importante que se estudem os métodos de estimativas de evapotranspiração. Um dos métodos mais utilizados para a estimativa da evapotranspiração é o método do tanque Classe A, no qual se mede o efeito integrado da radiação solar, vento, temperatura e umidade relativa sobre a evaporação de uma superfície livre de água, onde a planta responde às mesmas variáveis climáticas (KLAR, 1991).

O êxito na formação de florestas de alta produção depende, em grande parte, da qualidade das mudas plantadas que deverão sobreviver, tendo de resistir a condições adversas no campo, após o plantio, para produzir árvores com crescimento volumétrico economicamente desejável (GOMES et al., 1991).

A sobrevivência, o estabelecimento, a freqüência dos tratos culturais e o crescimento inicial das florestas são avaliações necessárias para o sucesso do empreendimento florestal, o que está diretamente relacionado com a qualidade das mudas por ocasião do plantio (GOMES et al., 1991; FONSECA, 2000), merecendo ressaltar que o potencial genético, as condições fitossanitárias e a conformação do sistema radicular são importantes para a boa produtividade dos povoamentos florestais (CARVALHO, 1992).

A aplicação agronômica do composto de lixo urbano, quando obtido de modo adequado, é viável devido a sua riqueza em matéria orgânica e nutriente, à ausência de microrganismos patogênicos (XIN et al., 1992; MELO et al., 1997; CRAVO et al., 1998) e às melhorias das condições de cultivo do solo (aumento do teor de matéria orgânica, elevação do pH, redução da acidez potencial e aumento da disponibilidade de fósforo, potássio, cálcio e magnésio), da nutrição e produção dos vegetais (KIEHL, 1985; LIMA et al., 1999; OLIVEIRA, 2000; ABREU JÚNIOR et al., 2000). 
Considerando os problemas advindos da geração de resíduos orgânicos urbanos, o presente trabalho teve por objetivo estudar o efeito da utilização de lixo orgânico e de irrigação no desenvolvimento de mudas de eucalipto e oferecer subsídios para o aproveitamento dessa parte de matéria orgânica na agricultura.

\section{MATERIAL E MÉTODOS}

O experimento foi desenvolvido a campo, na Área Demonstrativa e Experimental de Irrigação, do Departamento de Engenharia Rural, da UNESP, Jaboticabal - SP, localizada nas coordenadas $21^{\circ} 15^{\prime} 22^{\prime \prime}$ latitude sul e $48^{\circ} 18^{\prime} 58^{\prime \prime}$ longitude oeste, à altitude média de $575 \mathrm{~m}$ (IBGE, 1971).

A classificação climática para a região, segundo Köeppen, é Cwa: subtropical, com verão úmido e inverno relativamente seco. A temperatura média anual é de aproximadamente $22,2{ }^{\circ} \mathrm{C}$, sendo que, nos meses de junho e julho, se aproxima de $12,6^{\circ} \mathrm{C}$ e, de dezembro a fevereiro, se aproxima de $30,1^{\circ} \mathrm{C}$. A umidade relativa média do ar é de $75 \%$, podendo atingir $15 \%$ nos meses mais secos. A precipitação pluviométrica média anual é $1.430 \mathrm{~mm}$, sendo que $85 \%$ das chuvas ocorrem de outubro a março.

O delineamento experimental utilizado foi o inteiramente casualizado, num esquema fatorial $(2 \times 11 \times 4 \times 5)$, com três repetições. Os fatores consistiram de: dois tipos de controle da irrigação, um com base no método do tanque Classe A (considerando Kp igual 0,75 e Kc igual 1,1) e outro no método da pesagem para a estimativa da evapotranspiração (ET), conforme BERNARDO (1987) (Tabela 1); 11 substratos (Tabela 2), quatro níveis de irrigação (50; 75; 100 e $130 \%$ da lâmina calculada com base nos métodos de estimativa da ET) e cinco épocas (aos 15; 29; 41; 53 e 79 dias da semeadura). Cada parcela continha 32 tubetes de plástico, em forma de cone, medindo $125 \mathrm{~mm}$ de altura e $27 \mathrm{~mm}$ de diâmetro na parte superior, perfurados na parte inferior e apoiados em bandejas plásticas.

O R.S.O.U. foi obtido a partir da coleta aleatória do resíduo sólido urbano (R.S.U.) em um bairro de classe média-alta, na cidade de Jaboticabal - SP. As múltiplas coletas foram homogeneizadas e selecionadas, resultando nas frações inorgânica e orgânica. A fração inorgânica foi inutilizada e a fração orgânica (restos de alimentos, cascas de frutas, etc.) foi colocada em bandejas e levada à estufa com circulação de ar forçada, à temperatura de $70{ }^{\circ} \mathrm{C}$, até adquirir massa constante. Após a secagem, o material foi triturado em triturador de grãos modelo DPM-4 e passado em peneira de furo redondo de diâmetro de $2 \mathrm{~mm}$, denominando-se de R.S.O.U. Não foi feita a compostagem para verificar os efeitos sem a realização desse processo, ganhando-se tempo e diminuindo-se os custos.

Os substratos foram submetidos a análises granulométrica e química, realizadas nos laboratórios do Departamento de Solos e Adubos da UNESP - Jaboticabal. As análises granulométricas foram realizadas por meio do método da pipeta, utilizando-se de $\mathrm{NaOH} 0,1 \mathrm{~mol} \mathrm{~L}^{-1}$ como dispersante, tempo de repouso de 24 horas e agitação lenta, sendo as frações determinadas segundo DAY (1965).

As análises químicas referentes às determinações de acidez trocável $\left(\mathrm{Al}^{3+}\right)$, de macronutrientes (cálcio, magnésio, potássio trocáveis e fósforo disponível) e de micronutrientes (B, $\mathrm{Cu}, \mathrm{Fe}, \mathrm{Mn}$ e $\mathrm{Zn}$ ) foram realizadas, utilizando-se dos métodos descritos por RAIJ et al. (1987). O pH foi determinado potenciometricamente, utilizando a relação solo: $\mathrm{CaCl}_{2}$ 0,01 M, 1:2,5. Para a determinação do carbono orgânico, seguiu-se a metodologia EMBRAPA (1979). Os resultados da análise granulométrica dos solos e do R.S.O.U. encontram-se na Tabela 3, e os resultados das características químicas dos solos e do R.S.O.U. encontram-se na Tabela 4. 
TABELA 1. Lâmina de água aplicada $(\mathrm{mm})$ e precipitação $(\mathrm{P})$.

\begin{tabular}{|c|c|c|c|c|c|c|c|c|c|}
\hline \multirow{3}{*}{ Período } & \multirow{3}{*}{$\mathrm{P}(\mathrm{mm})$} & \multicolumn{8}{|c|}{ Irrigação (mm) } \\
\hline & & \multicolumn{2}{|c|}{$50 \%$ ET } & \multicolumn{2}{|c|}{$75 \%$ ET } & \multicolumn{2}{|c|}{$100 \% \mathrm{ET}$} & \multicolumn{2}{|c|}{$130 \% \mathrm{ET}$} \\
\hline & & TCA & PS & TCA & PS & TCA & PS & TCA & PS \\
\hline 16-nov. & 0,0 & 3,8 & 9,1 & 5,7 & 13,7 & 7,7 & 18,2 & 9,9 & 23,2 \\
\hline 17 & 0,0 & 4,1 & 6,3 & 6,2 & 9,4 & 8,2 & 12,5 & 10,7 & 15,9 \\
\hline 18 & 0,0 & 3,2 & 7,2 & 4,8 & 10,8 & 6,4 & 14,5 & 8,3 & 18,5 \\
\hline 19 & 0,0 & 3,6 & 4,8 & 5,3 & 7,2 & 7,1 & 9,6 & 9,2 & 12,3 \\
\hline 20 & 1,9 & 3,8 & 5,5 & 5,7 & 8,2 & 7,6 & 10,9 & 9,9 & 14,0 \\
\hline 21 & 0,0 & 3,1 & 3,3 & 4,7 & 4,9 & 6,2 & 6,5 & 8,0 & 8,3 \\
\hline 22 & 0,4 & 1,9 & 5,7 & 2,9 & 8,6 & 3,8 & 11,5 & 4,9 & 14,6 \\
\hline 23 & 0,0 & 2,7 & 3,2 & 4,0 & 4,8 & 5,5 & 6,5 & 7,0 & 8,2 \\
\hline 24 & 0,2 & 2,3 & 5,9 & 3,5 & 8,8 & 4,5 & 11,7 & 6,0 & 15,0 \\
\hline 25 & 0,3 & 3,6 & 6,1 & 5,4 & 9,2 & 7,2 & 12,3 & 9,3 & 15,7 \\
\hline 26 & 0,0 & 4,0 & 2,8 & 6,0 & 4,2 & 7,9 & 5,6 & 10,2 & 7,1 \\
\hline 27 & 0,0 & 2,6 & 6,9 & 3,9 & 10,4 & 5,2 & 13,8 & 6,6 & 17,6 \\
\hline 28 & 0,0 & 4,0 & 6,9 & 6,0 & 10,3 & 8,1 & 13,8 & 10,2 & 17,5 \\
\hline 29 & 0,0 & 4,2 & 8,5 & 6,3 & 12,7 & 8,5 & 16,9 & 10,7 & 21,6 \\
\hline 30 & 0,0 & 4,9 & 8,5 & 7,3 & 12,7 & 9,8 & 16,9 & 12,5 & 21,6 \\
\hline $1^{\mathrm{o}}-\mathrm{dez}$ & 0,0 & 4,3 & 8,4 & 6,4 & 12,5 & 8,6 & 16,7 & 11,0 & 21,3 \\
\hline 2 & 0,0 & 4,9 & 7,5 & 7,3 & 11,3 & 9,8 & 15,1 & 12,5 & 19,2 \\
\hline 3 & 9,4 & 4,6 & 3,6 & 6,9 & 5,5 & 9,2 & 7,3 & 11,7 & 9,3 \\
\hline 4 & 30,5 & - & - & - & - & - & - & - & - \\
\hline 5 & 0,0 & - & - & - & - & - & - & - & - \\
\hline 6 & 5,0 & 3,2 & 3,3 & 4,8 & 4,9 & 6,4 & 6,5 & 8,2 & 8,3 \\
\hline 7 & 3,8 & 0,9 & 1,2 & 1,3 & 1,8 & 1,9 & 2,4 & 2,3 & 4,2 \\
\hline 8 & 75,3 & - & - & - & - & - & - & - & - \\
\hline 9 & 1,0 & - & - & - & - & - & - & - & - \\
\hline 10 & 30,3 & - & - & - & - & - & - & - & - \\
\hline 11 & 0,6 & - & - & - & - & - & - & - & - \\
\hline 12 & 21,0 & - & - & - & - & - & - & - & - \\
\hline 13 & 21,4 & - & - & - & - & - & - & - & - \\
\hline 14 & 9,1 & - & - & - & - & - & - & - & - \\
\hline 15 & 0,0 & 2,5 & 6,1 & 3,7 & 9,1 & 4,9 & 12,2 & 6,4 & 15,5 \\
\hline 16 & 0,0 & 2,8 & 7,0 & 4,2 & 10,5 & 5,6 & 13,9 & 7,1 & 17,8 \\
\hline 17 & 0,0 & 4,5 & 7,2 & 6,7 & 10,8 & 8,9 & 14,4 & 11,5 & 18,3 \\
\hline 18 & 0,0 & 3,5 & 8,3 & 5,2 & 12,4 & 7,0 & 16,6 & 8,9 & 21,1 \\
\hline 19 & 0,0 & 3,3 & 8,2 & 4,9 & 12,3 & 6,6 & 16,4 & 8,4 & 21,0 \\
\hline 20 & 3,0 & 3,7 & 7,1 & 5,5 & 10,6 & 7,4 & 14,2 & 9,4 & 18,1 \\
\hline 21 & 0,0 & 3,5 & 7,6 & 5,2 & 11,4 & 7,1 & 15,2 & 8,9 & 19,4 \\
\hline 22 & 6,0 & 3,3 & 6,2 & 4,9 & 9,4 & 6,6 & 12,5 & 8,4 & 15,9 \\
\hline 23 & 16,0 & - & - & - & - & - & - & - & - \\
\hline 24 & 0,0 & - & - & - & - & - & - & - & - \\
\hline 25 & 0,0 & 3,1 & 7,5 & 4,6 & 11,2 & 6,1 & 14,9 & 7,9 & 19,0 \\
\hline 26 & 0,0 & 2,3 & 6,5 & 3,4 & 7,8 & 4,7 & 13,0 & 5,8 & 16,6 \\
\hline 27 & 0,0 & 3,3 & 7,5 & 4,9 & 11,3 & 6,6 & 15,0 & 7,4 & 19,2 \\
\hline 28 & 0,0 & 1,8 & 6,2 & 2,7 & 9,2 & 3,5 & 12,3 & 4,6 & 15,7 \\
\hline 29 & 0,0 & 2,4 & 7,2 & 3,6 & 10,8 & 4,9 & 14,4 & 6,1 & 18,3 \\
\hline 30 & 0,0 & 1,8 & 6,1 & 2,7 & 9,2 & 3,6 & 12,3 & 4,6 & 15,7 \\
\hline 31 & 4,3 & 4,5 & 5,0 & 6,7 & 7,4 & 9,0 & 9,9 & 11,5 & 12,7 \\
\hline $1^{\mathrm{o}}$-jan. & 64,0 & 2,9 & 3,6 & 4,3 & 5,5 & 5,8 & 7,3 & 7,4 & 9,3 \\
\hline Total & 302,8 & 118,9 & 221,8 & 178,4 & 332,8 & 237,8 & 443,7 & 302,2 & 565,7 \\
\hline
\end{tabular}


TABELA 2. Composição dos substratos.

\begin{tabular}{cc}
\hline Substratos & Composição \\
\hline S1 & Solo A em condição natural \\
S2 & Solo B em condição natural \\
S3 & Solo A com adubação química \\
S4 & Solo B com adubação química \\
S5 & Mistura de $80 \%$ de solo A e 20\% de R.S.O.U. \\
S6 & Mistura de $80 \%$ de solo B e 20\% de R.S.O.U. \\
S7 & Mistura de $60 \%$ de solo A e 40\% de R.S.O.U. \\
S8 & Mistura de 60\% de solo B e 40\% de R.S.O.U. \\
S9 & Mistura de $20 \%$ de solo A e 80\% de R.S.O.U. \\
S10 & Mistura de $20 \%$ de solo B e $80 \%$ de R.S.O.U. \\
S11 & R.S.O.U. puro \\
\hline
\end{tabular}

Solo A: Latossolo Vermelho eutrófico, típico textura argilosa, A moderado, caulinítico hipoférrico. Solo B: Latossolo Vermelho distrófico, típico textura arenosa, A moderado, caulinítico hipoférrico (EMBRAPA, 1999), ambos obtidos na profundidade de 0 a $30 \mathrm{~cm}$.

TABELA 3. Análise granulométrica dos solos e do R.S.O.U. empregados no experimento.

\begin{tabular}{lcrc}
\hline \multirow{2}{*}{ Classe } & Argila & Silte & Areia \\
\cline { 2 - 5 } & $\mathrm{g} \mathrm{kg}^{-1}$ & $\mathrm{~g} \mathrm{~kg}^{-1}$ & $\mathrm{~g} \mathrm{~kg}^{-1}$ \\
\hline Solo A & 530 & 230 & 340 \\
Solo B & 250 & 70 & 680 \\
R.S.O.U. & 130 & 410 & 460 \\
\hline
\end{tabular}

TABELA 4. Características químicas dos solos e do R.S.O.U. empregados no experimento.

\begin{tabular}{lcccccccccccccc}
\hline Solos & $\begin{array}{c}\mathrm{pH} \\
\mathrm{em} \mathrm{CaCl}\end{array}$ & $\begin{array}{c}\mathrm{M} . \mathrm{O} \\
\mathrm{g} \mathrm{dm}^{-3}\end{array}$ & $\begin{array}{c}\mathrm{P} \\
\mathrm{mg} \mathrm{dm}^{-3}\end{array}$ & $\mathrm{~K}$ & $\mathrm{Ca}$ & $\mathrm{Mg}$ & $\mathrm{H}+\mathrm{Al}$ & $\mathrm{SB}$ & $\mathrm{T}$ & $\mathrm{B}$ & $\mathrm{Cu}$ & $\mathrm{Fe}$ & $\mathrm{Mn}$ & $\mathrm{Zn}$ \\
\hline Solo A & 6,0 & 21 & 43 & 1,5 & 34 & 30 & 20 & 65,5 & 85,5 & 0,13 & 1,4 & 6,0 & 7,4 & 0,6 \\
Solo B & 4,4 & 15 & 15 & 1,6 & 12 & 5 & 38 & 18,6 & 56,6 & 0,13 & 0,4 & 14 & 5,5 & 0,3 \\
R.S.O.U. & 6,0 & 193 & 310 & 45 & 250 & 50 & 22 & 345 & 367 & 8,86 & 0,9 & 9,0 & 7,9 & 4,1 \\
\hline
\end{tabular}

Na semeadura, os tubetes de plástico preto, em forma de cone, medindo $125 \mathrm{~mm}$ de altura e $27 \mathrm{~mm}$ de diâmetro, na parte superior, perfurados nas extremidades inferiores, apoiadas em bandejas de 32 unidades, foram preenchidos manualmente, conforme os tratamentos. Inicialmente, as bandejas contendo os tubetes com os substratos foram emergidas em água, até o total encharcamento dos substratos. A seguir, foram retiradas, permitindo a percolação da água de todos os substratos, caracterizando, nesse momento, a capacidade de campo, quando foram semeadas quatro sementes por tubete e cobertas com camada de $2 \mathrm{~mm}$ de solo peneirado. $\mathrm{O}$ substrato foi coberto com sacos de aniagem, sendo retirados assim que as plântulas emergiram. O desbaste foi efetuado 15 dias após a semeadura, deixando uma muda por tubete.

Os tratamentos dos solos com adubação química (S3 e S4) consistiram da adubação foliar Nutri-Rápido (NPK + micronutrientes), na formulação 16-32-16, aplicando-se $25 \mathrm{~mL}$ por tubete cada vez, aos 35 e aos 42 dias após a semeadura, nas dosagens respectivas de $1 \%$ e $4 \%$ de adubo foliar, sendo essa última acrescida de salitre do Chile, uréia e $\mathrm{KCl}$. Todos os tratamentos receberam, aos 56 dias, junto à rega, 0,05 g de Salitre do Chile, e aos 63 dias, uma rega com $1 \%$ de uréia e $1 \%$ de $\mathrm{KCl}$.

Após a semeadura, os substratos foram colocados em capacidade de campo e, durante 30 dias, receberam duas irrigações diárias, conforme rotina de um viveiro de mudas. Após esse período, os substratos foram colocados novamente em capacidade de campo e iniciada a irrigação com regadores manuais em aspersão, baseada nos dois métodos de controle.

A área do experimento foi mantida isenta de plantas daninhas por meio de arranquio manual nos tubetes e de capinas manuais nas imediações das bandejas-suporte dos tubetes. Nenhum defensivo químico foi utilizado para o combate das plantas daninhas, pragas e doenças. 
Para a determinação do número de tubetes com plantas vivas, foram efetuadas contagens aos 15; 29; 41; 53 e 79 dias após a semeadura. Nessas mesmas datas, em dez plantas por tratamento, em todas as parcelas, foram determinados a altura média, considerando-se a distância do colo da planta à extremidade da folha que atingiu a maior distância da base da planta e o número médio de folhas por planta.

As análises estatísticas foram realizadas pelo procedimento PROC GLM do SAS, sendo as comparações de médias realizadas utilizando-se do teste de Tukey, a 5\% de probabilidade.

\section{RESULTADOS E DISCUSSÃO}

Comparando o número médio de tubetes com plantas vivas em diferentes épocas após a semeadura (Tabelas 5 e 6), verificou-se que, aos 15 e 29 dias, os substratos estudados não apresentaram diferenças significativas. Verificou-se que, aos 41 dias, somente o substrato S11 apresentou diferença significativa no número de plantas vivas. Aos 53 e 79 dias, somente os substratos S9, S10 e S11 diferiram estatisticamente dos demais. As diferenças, segundo GALBIATTI (1992), podem estar associadas aos tipos de matéria orgânica ativa e inativa.

TABELA 5. Valores de F e coeficientes de variação (C.V.) obtidos na análise de variância para número de tubetes com plantas vivas e altura de plantas.

\begin{tabular}{lcc}
\hline \multicolumn{1}{c}{$\mathrm{F}$} & Tubetes com Plantas Vivas & Altura de Plantas \\
\hline Tipo de irrigação (TI) & $1.176,23^{* *}$ & $55,58^{* *}$ \\
Substrato (SB) & $47,92^{* *}$ & $287,94^{* *}$ \\
Idade (ID) & $210,36^{* *}$ & $1287,98^{* *}$ \\
Nível de irrigação (NI) & $13,90^{* *}$ & $4,33^{* *}$ \\
Interação (TIxSB) & $23,21^{* *}$ & $3,72^{* *}$ \\
Interação (TIxID) & $4,00^{* *}$ & $0,17^{\mathrm{NS}}$ \\
Interação (TIxNI) & $1,19^{\mathrm{NS}}$ & $2,32^{*}$ \\
Interação (SBxID) & $15,83^{* *}$ & $15,27^{* *}$ \\
Interação (SBxNI) & $2,75^{* *}$ & $0,96^{\mathrm{NS}}$ \\
Interação (IDxNI) & $2,13^{*}$ & $3,23^{* *}$ \\
Interação (TIxSBxID) & $0,34^{\mathrm{NS}}$ & $1,68^{*}$ \\
Interação (TIxSBxNI) & $2,61^{* *}$ & $1,33^{\mathrm{NS}}$ \\
Interação (SBxIDxNI) & $0,21^{\mathrm{NS}}$ & $0,43^{\mathrm{NS}}$ \\
Interação (TIxSBxIDxNI) & $0,22^{\mathrm{NS}}$ & $0,39^{\mathrm{NS}}$ \\
\hline C.V. (\%) & 9,11 & 12,23 \\
\hline
\end{tabular}

TABELA 6. Número médio de tubetes com plantas vivas, avaliado aos 15; 29; 41; 53 e 79 dias após a semeadura.

\begin{tabular}{cccccc}
\hline \multirow{2}{*}{ Substrato } & \multicolumn{7}{c}{ Avaliações } \\
\cline { 2 - 6 } & 15 & \multicolumn{7}{c}{41} & \multicolumn{1}{c}{53} & 79 \\
\hline S1 & 23,04 a A & 23,50 a A & 22,00 a AB & 20,42 a A & 19,17 a A \\
S2 & 25,10 a A & 24,92 a A & 23,13 a AB & 22,21 a A & 21,54 a A \\
S3 & 22,38 a A & 22,25 a A & 20,42 a AB & 18,17 a AB & 17,25 a A \\
S4 & 26,46 a A & 26,13 a A & 25,42 a A & 23,50 a A & 22,54 a A \\
S5 & 25,21 a A & 26,08 a A & 24,92 a AB & 23,38 a A & 22,42 a A \\
S6 & 22,54 a A & 23,04 a A & 21,46 a AB & 19,96 a A & 18,71 a A \\
S7 & 23,67 a A & 23,96 a A & 22,63 a AB & 20,92 a A & 19,21 a A \\
S8 & 23,88 a A & 24,42 a A & 22,96 abAB & 19,88 abA & 17,92 bA \\
S9 & 25,71 a A & 27,17 a A & 24,12 a AB & 13,54 b B & 10,71 b B \\
S10 & 25,33 a A & 26,38 a A & 23,79 a AB & 13,58 b B & 3,50 c B \\
S11 & 24,33 a A & 25,71 a A & 19,21 b B & 3,50 c B & 1,92 c C \\
\hline C.V.\% & 8,11 & 10,2 & 13,4 & 11,72 & 15,6 \\
\hline
\end{tabular}

Médias seguidas de mesma letra, minúscula (na linha) e maiúscula (na coluna), não diferem entre si, pelo Teste de Tukey, a 5\% de probabilidade. C.V.: coeficiente de variação. 
Para as variáveis altura média de plantas (Figura 1) e número médio de folhas por planta (Figura 2), avaliadas aos 79 dias após a semeadura, a adição crescente de R.S.O.U. nos substratos (de 20 a 100\%) apresentou efeito negativo proporcional às quantidades utilizadas, entretanto o crescimento foi homogêneo em todos os substratos, nas diferentes idades.

Deve-se, portanto, atentar-se para o fato de que aplicações sucessivas e em elevadas doses do composto de lixo, sem o devido monitoramento, podem causar efeitos negativos ao solo e às plantas. A salinização, avaliada pela condutividade elétrica (GARCIA et al., 1992; ABREU JÚNIOR et al., 2000), o acúmulo de metais (CRAVO et al., 1998), a lixiviação de nitratos (OLIVEIRA, 2000) e a dispersão dos colóides e a redução da condutividade hidráulica do solo, decorrentes da substituição do cálcio e magnésio da interface solução do solo-superfície coloidal pelo sódio e potássio, presentes em altas concentrações no composto de lixo (MELO et al., 1997), são os principais aspectos ambientais a serem monitorados para o sucesso dessa prática.

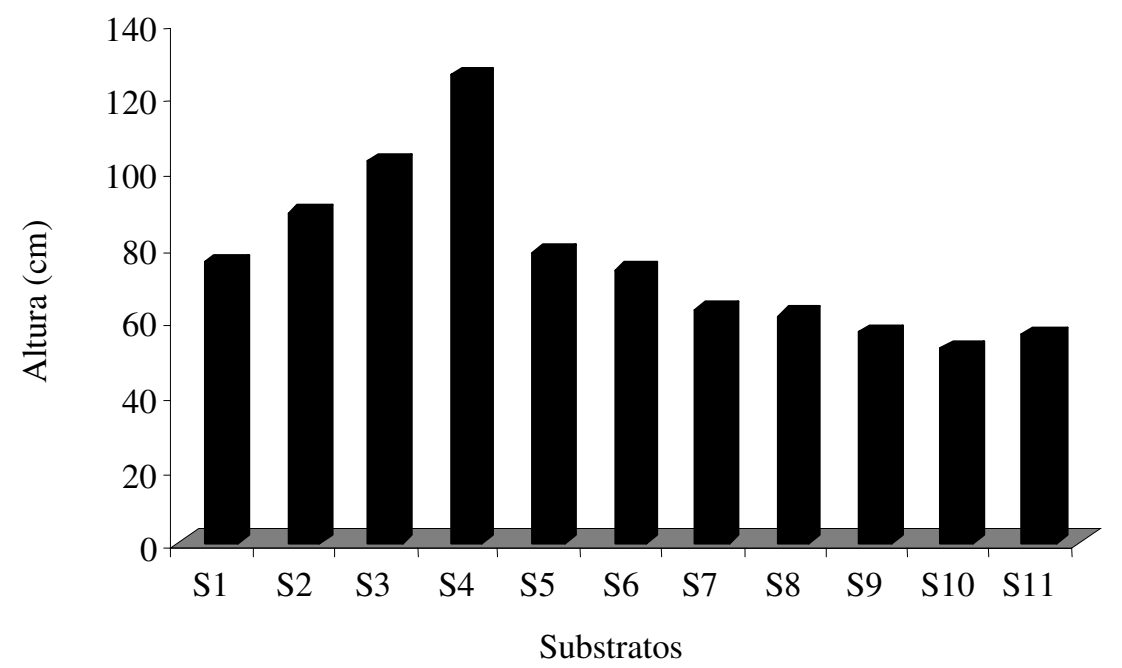

FIGURA 1. Altura média de plantas (cm), avaliada aos 79 dias após a semeadura.

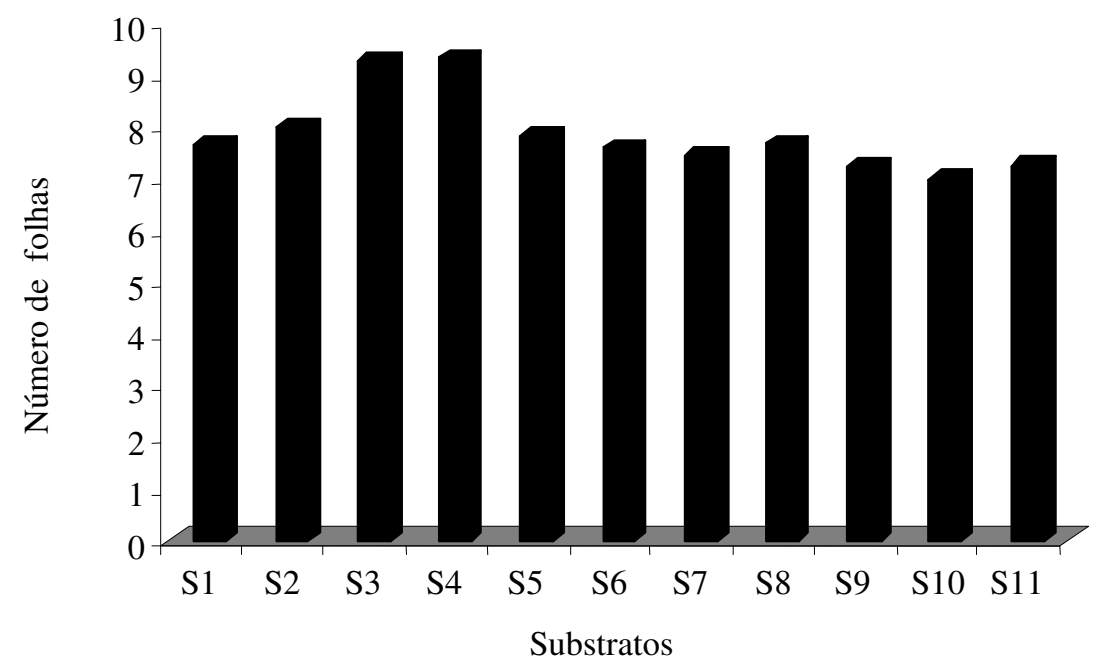

FIGURA 2. Número médio de folhas por planta, avaliado aos 79 dias após a semeadura.

Analisando a interação entre os substratos e os tipos de irrigação (Tabela 5), e os valores médios do número de tubetes com plantas vivas, em função do tipo de irrigação (TCA e PS) (Tabela 7), verifica-se que, na irrigação conduzida pelo método do tanque Classe A, o S5 foi o que apresentou maior número médio de tubetes com plantas vivas, não apresentando diferença estatística com S2 e S4. No método de condução da irrigação pela variação de massa, o maior número de tubetes com plantas vivas foi identificado no $S 2$, observando-se diferença estatística somente em relação aos tratamentos S9, S10 e S11, que proporcionaram menor número de plantas vivas. Exceto para o S11, o método de condução da irrigação pela variação de massa, foi superior ao método do tanque Classe A. 
TABELA 7. Valores médios do número de tubetes com plantas vivas, em função do tipo de irrigação (TCA e PS).

\begin{tabular}{|c|c|c|}
\hline \multirow{2}{*}{ Substrato } & \multicolumn{2}{|c|}{ Tipo de Irrigação } \\
\hline & TCA & PS \\
\hline S1 & 17,33 b $\quad$ CD & $25,93 \mathrm{aAB}$ \\
\hline $\mathrm{S} 2$ & 18,28 bABC & $28,48 \mathrm{aA}$ \\
\hline S3 & $14,00 \quad b$ & $26,18 \mathrm{aABC}$ \\
\hline S4 & 21,42 bAB & $28,20 \mathrm{aA}$ \\
\hline S5 & 21,68 bA & $27,12 \mathrm{aA}$ \\
\hline S6 & $15,80 \quad \mathrm{~b} \quad \mathrm{CD}$ & $26,48 \mathrm{aAB}$ \\
\hline S7 & $16,25 \quad b \quad C D$ & $27,90 \mathrm{aA}$ \\
\hline S8 & $16,15 \quad b \quad C D$ & $27,47 \mathrm{aA}$ \\
\hline S9 & 17,78 b BC & 22,75 a $\quad C$ \\
\hline S10 & $15,87 \quad b \quad C D$ & 23,32 a $\mathrm{BC}$ \\
\hline S11 & $15,12 \mathrm{a} \quad \mathrm{CD}$ & 14,75 a $\quad D$ \\
\hline
\end{tabular}

Médias seguidas de mesma letra, minúscula (na linha) e maiúscula (na coluna), não diferem entre si, pelo Teste de Tukey, a $5 \%$ de probabilidade.

À medida que se aumentou a percentagem de R.S.O.U., foi menor o desenvolvimento em altura das plantas e o número médio de folhas por planta. $\mathrm{O}$ efeito prejudicial ao desenvolvimento das plantas pode ser pelo fato de o R.S.O.U. ter sido utilizado logo após a secagem em estufa. De acordo com KIEHL (1985), o composto orgânico utilizado como fertilizante resulta de processo de decomposição bioquímica de materiais orgânicos, transformado em um produto mais estável.

COSTA et al. (2001) obtiveram aumento linear na produção de matéria fresca da hortaliça, aumento significativo nos teores de zinco da parte aérea e nenhum efeito nos de cobre, níquel e chumbo, com a aplicação de composto de lixo urbano.

Ao comparar o número de tubetes com plantas vivas nos diferentes substratos e níveis de irrigação (Tabela 8), verifica-se que, no nível de $50 \%$ da evapotranspiração, o substrato S11 apresentou o menor número de tubetes com plantas vivas, embora não diferindo estatisticamente dos substratos S3, S6, S9 e S10.

TABELA 8. Número médio de tubetes com plantas vivas nos substratos, em cada nível de irrigação, aos 79 dias.

\begin{tabular}{|c|c|c|c|c|}
\hline \multirow{2}{*}{ Substrato } & \multicolumn{4}{|c|}{ Nível de Irrigação } \\
\hline & $50 \%$ & $75 \%$ & $100 \%$ & $130 \%$ \\
\hline S1 & 22,63 a $\mathrm{A}$ & 23,00 a $A B$ & 21,70 a $\mathrm{ABC}$ & 19,17 a $\mathrm{AB}$ \\
\hline S2 & 22,53 a $\mathrm{A}$ & 23,18 a $A B$ & 24,20 a $\mathrm{AB}$ & 23,60 a $\mathrm{A}$ \\
\hline S3 & 18,07 a $\mathrm{AB}$ & 21,90 a $A B$ & 20,77 a $\mathrm{ABC}$ & 19,63 a $\mathrm{AB}$ \\
\hline $\mathrm{S} 4$ & 20,93 bA & 26,83 a $\mathrm{A}$ & 26,23 a $A$ & 25,23 a $A$ \\
\hline S5 & 22,17 bA & 26,03 a $A B$ & $24,47 \mathrm{abAB}$ & $24,93 \mathrm{abA}$ \\
\hline S6 & 20,67 a $A B$ & 20,33 a $B$ & 20,43 a $\mathrm{AB}$ & 23,13 a $\mathrm{A}$ \\
\hline S7 & 21,30 a $\mathrm{A}$ & 21,47 a $\mathrm{AB}$ & 22,43 a $\mathrm{AB}$ & 23,10 a $\mathrm{A}$ \\
\hline S8 & 20,87 a $\mathrm{A}$ & 22,05 a $A B$ & 23,13 a $\mathrm{AB}$ & 20,73 a $\mathrm{AB}$ \\
\hline S9 & 18,73 a $A B$ & 23,00 a $A B$ & 20,37 a $\mathrm{AB}$ & 18,97 a $\mathrm{AB}$ \\
\hline S10 & 18,97 a $\mathrm{AB}$ & $20,30 \mathrm{a} \quad \mathrm{B}$ & $19,67 \mathrm{a}$ & 19,43 a $\mathrm{AB}$ \\
\hline S11 & $14,10 \mathrm{a}$ & 14,07 a $\mathrm{AC}$ & $16,53 \mathrm{a}$ & $15,03 \mathrm{a}$ \\
\hline
\end{tabular}

Médias seguidas de mesma letra, minúscula (na linha) e maiúscula (na coluna), não diferem entre si, pelo Teste de Tukey, a $5 \%$ de probabilidade.

No nível de irrigação $75 \%$ da evapotranspiração, o melhor resultado observado foi no S4, embora diferenciando estatisticamente apenas de S6, S10 e S11. Para o nível de irrigação de 100\% 
da evapotranspiração, o substrato que melhor se comportou em relação ao número de tubetes com plantas vivas foi o S4, embora tenha apenas diferido estatisticamente do S10. O substrato S11 foi o que apresentou menor número de tubetes com plantas vivas, no nível de irrigação de $130 \%$ da evapotranspiração, embora não diferindo estatisticamente dos substratos S1, S3, S9 e S10. Os substratos de S1 a S10 não apresentaram diferença estatística.

Os resultados mostram que o aumento na quantidade de água aplicada proporcionou maior número de tubetes com plantas vivas, havendo relação direta entre os níveis de água e o número de tubetes com plantas vivas, apesar de, estatisticamente, ter sido significativo apenas no substrato S5. O efeito físico causado pela matéria orgânica no solo é importante para o desenvolvimento dos vegetais; segundo HENIN et al. (1976), seu efeito na melhoria da estrutura do solo constitui fator positivo para o desenvolvimento das raízes. Essa melhoria está relacionada, também, com o regime de água, pois, melhorando a capacidade de infiltração, acelera o processo dinâmico da água no solo.

Conforme observado na Tabela 9, o número de tubetes com plantas vivas pelo método de controle da irrigação da pesagem obteve melhores resultados do que pelo tanque Classe $\mathrm{A}$, em qualquer das épocas de avaliação. O número de folhas por planta foi crescente com o aumento da idade das mudas, nos dois métodos de condução da irrigação, sendo que, na análise aos 79 dias após a semeadura, o crescimento foi maior pelo método da irrigação do tanque Classe A (Tabela 9). Esse efeito pode ser explicado pela grande diferença de lâmina de água aplicada (quase $100 \%$ a mais para o método da pesagem), aumentando a lixiviação com conseqüentes perdas de nutrientes.

TABELA 9. Número médio de tubetes com plantas vivas e número médio de folhas por plantas em função do tipo de irrigação e da época de avaliação (dias após a semeadura).

\begin{tabular}{lccrrrr}
\hline \multirow{2}{*}{ Variável } & \multirow{2}{*}{ TI } & \multicolumn{5}{c}{ Idade } \\
\cline { 3 - 7 } & TCA & $20,55 \mathrm{bA}$ & $20,29 \mathrm{bA}$ & $18,10 \mathrm{bB}$ & $14,42 \mathrm{bC}$ & $12,86 \mathrm{bC}$ \\
\multirow{2}{*}{ Tubetes com plantas vivas } & PS & $28,11 \mathrm{aB}$ & $29,45 \mathrm{aA}$ & $27,38 \mathrm{aB}$ & $21,77 \mathrm{aC}$ & $19,92 \mathrm{aC}$ \\
\hline \multirow{2}{*}{ Folhas por planta } & TCA & - & $4,58 \mathrm{bD}$ & $6,00 \mathrm{bC}$ & $7,01 \mathrm{aB}$ & $8,18 \mathrm{bA}$ \\
& PS & - & $4,85 \mathrm{aC}$ & $6,75 \mathrm{aB}$ & $6,68 \mathrm{aB}$ & $7,53 \mathrm{aA}$ \\
\hline
\end{tabular}

$\overline{\text { Médias seguidas da mesma letra, na coluna (maiúscula) e na linha (minúscula), não diferem entre si, pelo Teste de }}$ Tukey (5\%). TI - tipo de método de cálculo da irrigação. TCA - tanque Classe A. PS - determinação da massa.

Finalmente, em relação à altura média de plantas, não se constataram diferenças estatísticas significativas entre os níveis de irrigação, como também para o método de cálculo da quantidade de irrigação (Tabela 10).

TABELA 10. Altura média de plantas (mm), analisadas em função da irrigação.

\begin{tabular}{lccccc}
\hline \multirow{2}{*}{ Variável } & \multirow{2}{*}{ TI } & \multicolumn{4}{c}{ Níveis de Irrigação (\%ET) } \\
\cline { 3 - 6 } & & 50 & 75 & 100 & 130 \\
\hline \multirow{2}{*}{ Altura de plantas } & TCA & $46,17 \mathrm{aA}$ & $48,29 \mathrm{aA}$ & $46,54 \mathrm{aA}$ & $48,57 \mathrm{aA}$ \\
& PS & $49,03 \mathrm{aA}$ & $52,41 \mathrm{aA}$ & $52,69 \mathrm{aA}$ & $50,97 \mathrm{aA}$ \\
\hline
\end{tabular}

Médias seguidas da mesma letra, na coluna (maiúscula) e na linha (minúscula), não diferem entre si, pelo Teste de Tukey (5\%); TI - tipo de método de cálculo da irrigação; TCA - tanque Classe A; PS - determinação da massa.

\section{CONCLUSÕES}

Para níveis de irrigação, as misturas de R.S.O.U. não diferiram estatisticamente para a maior parte dos tratamentos; contudo, para os demais valores, constatou-se que misturas a partir de $20 \%$ de R.S.O.U. apresentam tendência de diminuir o número de plantas vivas.

Existe relação direta entre adições de R.S.O.U., crescimento e número de folhas das plantas.

Doses acima de $20 \%$ de R.S.O.U., sem compostagem, na mistura em solos destinados à produção de mudas de eucalipto, causam efeitos negativos na sobrevivência das plantas. 
O método das pesagens para cálculo da irrigação é mais eficiente nas condições em que se desenvolveu este trabalho.

\section{REFERÊNCIAS}

ABREU JÚNIOR, C.H.; MURAOKA, T.; LAVORANTE, A.F.; ALVAREZ V. F.C.

Condutividade elétrica, reação do solo e acidez potencial em solos adubados com composto lixo. Revista Brasileira de Ciência do Solo, Viçosa, v.24, n.4, p.635-47, 2000.

ANDRIOLI, I.; SACCHI, E.; NISHIDA, L.T.; CENTURION, J.F. Efeito de modalidades de preparo e da aplicação de um composto orgânico nas propriedades físicas de um Latossolo Vermelho-Escuro textura média nas culturas de soja e milho. In: CONGRESSO BRASILEIRO DE CIÊNCIA DO SOLO, 23., 1991, Porto Alegre. Anais... Porto Alegre: Sociedade Brasileira de Ciência do Solo, 1991. p.143.

BERNARDO, S. Manual de irrigação. 4.ed. Viçosa: UFV, 1987. 488 p.

CARVALHO, C.M.; NOVAES, A.B.D.; SÃO JOSÉ, A.R.; BARBOSA, A.A.; SOUZA, I.V.B. Produção de mudas de espécies florestais de rápido crescimento. In: NOVAES, A.B. Reflorestamento no Brasil. Vitória da Conquista: UESB, 1992. p.93-103.

COSTA, C.A.; CASALI, V.W.D.; RUIZ, H.A.; JORDÃO, C.P.; CECON, P.R. Teor de metais pesados e produção de alface adubada com composto de lixo urbano. Horticultura Brasileira, Brasília, v.19, n.1, p.10-16, 2001.

CRAVO, M.S.; MURAOKA, T.; GINE-ROSIAS, M.F.G. Caracterização química de compostos de lixo urbano de algumas usinas brasileiras. Revista Brasileira de Ciência do Solo, Viçosa, v.22, p.547-53, 1998.

DAY, P.R. Particle fracionation and particle - size analysis. In: BLACK, C.A. Methods of soil analysis. Madison: American Society of Agronomy, 1965. part 1, cap. 43, p.545-567. (ASA, 9).

EMBRAPA. EMPRESA BRASILEIRA DE PESQUISA AGROPECUÁRIA. Serviço Nacional de Levantamento e Conservação do Solo. Manual de métodos de solo. Rio de Janeiro, 1979. 247 p.

EMBRAPA. EMPRESA BRASILEIRA DE PESQUISA AGROPECUÁRIA. Centro Nacional de Pesquisa de Solos. Sistema Brasileiro de Classificação de Solos. Brasília, 1999. 412 p.

FERNANDEZ, J.E.; MORENO, F.; HERNANDÉZ, J.M.; MURILLO, J.M. Influencia del aporte continuado de resíduos sólidos urbanos sobre propriedades físicas del suelo. In: CONGRESSO NACIONAL DE QUÍMICA, 7., 1987, Sevilha. Anais... Sevilha, 1987. 1 CD-ROM.

FONSECA, E.P. Padrão de qualidade de mudas de Trema micrantha (L.) Blume Cedrela fissilis Vell. e Aspidosperma polyneuron Müll. Arg. produzidas sob diferentes períodos de sombreamento. 2000. 113 f. Tese (Doutorado em Produção Vegetal) - Faculdade de Ciências Agrárias e Veterinárias, Universidade Estadual Paulista, Jaboticabal, 2000.

GALBIATTI, J.A. Efeito do uso contínuo de efluente de biodigestos sobre algumas características físicas do solo e o comportamento do milho (Zea Mays L.). 1992. 212 f. Tese (Livre-Docência) Faculdade de Ciências Agrárias e Veterinárias, Universidade Estadual Paulista, Jaboticabal, 1992.

GARCIA, C.; HERNÁNDEZ, T.; COSTA, F.; PASCUAL, J.A. Phytotoxicity due to the agricultural use of urban wastes. Germination experiments. Journal Science Food Agricultural, New Jersey, v.59, n.3, p.313-19, 1992.

GOMES, J.M.; COUTO, L.; BORGES, R.C.C.; FONSECA, E.P. Efeito de diferentes substratos na produção de mudas de Eucalyptus grandis W. Hill ex Maiden, em "Win-Strip". Revista Árvore, Viçosa, v.15, n.1, p.35-42, 1991.

HENIN, S.; GRAS, R.; MONNIER, G. Os solos agrícolas. Rio de Janeiro: Forense, Universitária, 1976. $327 \mathrm{p}$. 
IBGE. INSTITUTO BRASILEIRO DE GEOGRAFIA E ESTATÍSTICA. Departamento de Cartografia. Carta do Brasil: Jaboticabal, Taiúva e Pitangueiras. São Paulo, 1971. Escala 1:50.000.

IBGE. INSTITUTO BRASILEIRO DE GEOGRAFIA E ESTATÍSTICA. Censo Demográfico 2000: Migração e Deslocamento. Brasília: Ministério de Planejamento, Orçamento e Gestão. Brasília, 2000.

KIEHL, E. J. Fertilizantes orgânicos. São Paulo: Agronômica Ceres, 1985. 492 p.

KLAR, A.E. Irrigação: frequência e quantidade de aplicação. São Paulo: Nobel, 1991. 156 p.

LARCHER, W. Ecofisiologia vegetal. São Carlos: RIMA, 2000. 531 p.

LIMA, J.S.; LICHTIG, J.; OLIVEIRA, E.; MENK, J.R.F. Hortaliças cultivadas com composto orgânico de lixo urbano não apresentam contaminação com metais pesados. Revista Ceres, Viçosa, v.46, p.571-85, nov./dez.1999.

MAROUELLI, W.A.; SILVA, W.L.C. Adequação da época de paralisação das irrigações em tomate industrial no Brasil Central. Horticultura Brasileira, Brasília, v.11, n.2, p.118-21, 1993.

MELO, W.J.; MARQUES, M.O.; SILVA, F.C.; BOARETTO, A.E. Uso de resíduos sólidos urbanos na agricultura e impactos ambientais. In: CONGRESSO BRASILEIRO DE CIÊNCIA DO SOLO, 26., 1997. Rio de Janeiro. Anais... Rio de Janeiro: EMBRAPA/SBCS, 1997. 1 CD-ROM.

OLIVEIRA, F.C. Disposição de lodo de esgoto e composto de lixo urbano num Latossolo Vermelho-Amarelo cultivado com cana-de-açúcar. Piracicaba, 2000. 247 f. Tese (Doutorado em Solos e Nutrição de Plantas) - Escola Superior de Agricultura "Luiz de Queiroz", Universidade de São Paulo, Piracicaba, 2000.

RAIJ, B. van; QUAGGIO, J.A.; CANTARELLA, H.; FERREIRA, M.E.; LOPES, A.S.; BATAGLIA, O.C. Análise química do solo para fins de fertilidade. Campinas: Fundação Cargill, 1987. 170 p.

RUIZ, H.A.; TEIXEIRA, E.A. Retenção de água em materiais de solos tratados com dois compostos orgânicos. In: CONGRESSO BRASILEIRO DE CIÊNCIA DO SOLO, 23., 1991, Porto Alegre. Anais... Porto Alegre: Sociedade Brasileira de Ciência do Solo, 1991.

XIN, T.H.; TRAINA, S.J.; LOGAN, T.J. Chemical properties of municipal solid waste compost. Journal of Environmental Quality, Madison, v.21, n.4, p.318-29, 1992. 